\title{
BREVES NOTAS ÀS CARTAS DE JOSÉ DE ANCHIETA
}

\author{
Eduardo Tomasevicius Filho \\ Doutorando em Direito Civil da Faculdade de \\ Direito da Universidade de São Paulo.
}

Resumo:

O presente texto analisa as cartas do fundador da cidade de São
Paulo José de Anchieta, por meio das quais ele conta como era a vida naquela Paulo, José de Anchieta, por meio das quais ele conta como era a vida naquela época c quais os problemas que cle notava ao tentar aplicar o direito europeu aos indios. Também se procurou tirar lições para os dias atuais, sobretudo em relação aos tipos de entidade familiar existentes no Brasil.

Abstract:

This text is an analysis on the letters of the São Paulo's founder, José de Anchicta, by which he relates how Brazilian Indians lived at that time, and what problems he challenged in the enforcement of European law to them. Furthermore, on tried to get some lessons to our days, in special about patterns of family entities in Brazil.

Unitermos: São Paulo; indios; casamento: concubinato; união estável; ineficácia das leis.

Keywords: Brazilian Indians; patterns of family; entities in Brazil.

Introdução

Em 25 de janeiro de 2004. dia em que se comemora a conversão do apóstolo São Paulo, nossa cidade celebrou 450 anos de fundação, que se deu formalmunte com a celebração de uma missa pelo jesuíta José de Anchieta em um colégio localizado próximo à nossa faculdade.

Para comemorar esta data, diversos eventos vêm sendo realizados ao longo deste ano. Um destes foi a exposição das cartas de Anchieta, nas quais ele conta sobre a fundação de São Paulo e como era a vida nesta região na segunda mutade do século 16 . Os visitantes desta exposição recebiam gratuitamente a coletânea "Minhas Cartas - Por José de Anchieta". na qual contém a transcrição de algumas delas. É muito interessante tomar contato com este material, já que, infelizmente. pouco se divulga sobre a história do direito brasileiro, em comparação com o direito europeu. 
Tendo em vista o aniversário da cidade de São Paulo, foi selecionada uma das cartas de Anchieta, escrita em São Paulo em setembro de 1554 considerada a certidão de batismo da cidade por meio da qual ele contava ao fundador da Companhia de Jesus, Santo Ignácio de Loyola, os motivos da fundação da cidade de São Paulo, e como era o modo de vida familiar dos índios e dos portugueses naquela época. As demais cartas foram usadas apenas para ilustrar o modo de ensino dos jesuítas aos índios. Contudo, procurou-se analisar os aspectos jurídicos que Anchieta notava, e tirar algumas lições para o presente.

\section{Contexto Histórico}

Antes de entrar diretamente na análise da carta de Anchieta, será feita uma breve introdução sobre os eventos que ocorreram e resultaram na fundação da cidade de São Paulo, e em que momento os jesuítas chegaram no Brasil.

a) Do Descobrimento do Brasil à Chegada dos Jesuítas

Logo após o descobrimento do Brasil, Portugal enviou expedições ao Brasil com o intuito de conhecer as terras então recém-descobertas por Pedro Álvares Cabral. No entanto, os navegadores portugueses que visitaram a costa brasileira com esta finalidade encontraram não só terras inexploradas, mas também franceses extraindo pau-brasil. (Abreu, 2000, p. 59-63).

Anos se passaram e tornou-se necessária a tomada da posse definitiva do Brasil. O Rei D. João III ordenou a divisão do Brasil em capitanias hereditárias. Um de seus conselheiros, Martim Afonso de Souza, recebeu duas capitanias (Pernambuco e São Vicente), bem como a missão de demarcar a costa de Pernambuco até o Rio da Prata, iniciando a colonização do Brasil. ${ }^{\prime}$

Martim Afonso, com efeito, foi a Pernambuco e lá deixou algumas pessoas. (Abreu, 2000, p. 65) Seguiu viagem em direção ao sul do Brasil. Em $1^{\circ}$ de janeiro de 1531, ele avistou um boqueirão, chamado pelos indios tamoios de Nicteroy; porém, este lugar recebeu o nome de Rio de Janeiro. (Madre de Deus,

1 O Alvará Régio do Rei D. João III, de 28 de sutembro de 1532, confuria poderes a Martim A fonso de Sousa para ceder sesmarias a quem tivesse escolhido viver por aqui. 
1975, p. 41). Como os índios tamoios não eram amistosos, seguiu sua viagem para o sul. Em 6 de janeiro, chegou a Angra dos Reis; dia 20 de janeiro, atingiu São Sebastião; e no dia 22 de janeiro, atingiu a região da baixada santista. Nesta região. Martim Afonso ancorou sua esquadra, e fundou a primeira cidade do Brasil, São Vicente. ${ }^{2}$ (Madre de Deus, 1975, p. 42).

Nesta região já vivia um português chamado João Ramalho. Provavelmente foi um dos primeiros degredados de Portugal para o Brasil. Era uma figura de destaque entre os índios guaianazes, que viviam na região chamada de Campo de Piratininga ${ }^{3}$ (Madre de Deus, 1975, p. 119) Embora fosse casado em Portugal, casnu-se aqui com a india Bartira, filha do cacique Tibiriçá, e com ela teve vários filhos. (Nobrega, 1553).

Os portugueses que para cá vieram queriam descobrir se havia minas de metais preciosos no interior. Meses após terem se instalado em São Vicente, o próprio Martim Afonso fundou uma vila na região onde ficava a aldeia do cacique Tibiriçá e de João Ramalho. Em 10 de outubro de 1531, passou-se a Pedro de Góis a sesmaria da região. (Madre de Deus, 1975, p. 91) Porém, Martim Afonso proibiu a entrada brusca de portugueses pelo "sertão" pois se temia que ocorresse o despovoamento do litoral paulista, e o aumento de conflitos com os índios.

Anos depois, em 8 de abril de 1553, fundou-se a vila de Santo André, que fica ao lado da aldeia no Campo de Piratininga, tendo sido nomeado como Alcaide-Mor o mesmo João Ramalho, que já exercia o cargo de Guarda-Mor do Campo. (Madre de Deus, 1975, p. 122).

b) A Companhia de Jesus e a Fundação de São Paulo

A Companhia de Jesus ou Socieras Jesu (S.J.) é uma ordem católica fundada pelo militar Santo Ignácio de Loyola em 1531. Foi reconhecida como ordem em 1540, ¿ tinha por objetivos espalhar a fé católica pelo mundo. Também se dedicava ao ensino. O foco da evangelização era as crianças.

\footnotetext{
. Martim Afonso de Sousa ancorou na Praia do Itararé, proximo à llha Porchat.

'. Esta região chamava-se Campo, em oposição à região beira-mar. Atualmente corresponde ao Município de São Bernardo do Campo.
} 
Os primeiros jesuitas chegaram ao Brasil em 1549, com o primeiro Governador-Geral do Brasil, Tomé de Souza (Madre De Deus, 1975, p. 123). O superior dos jesuitas no Brasil era o Padre Manoel da Nóbrega.

Eles estavam divididos em diversos grupos ao longo da costa brasileira. Em São Vicente, o responsável pela companhia era o Padre Leonardo Nunes, que fundou um colégio para catequizar os meninos indígenas. (Madre de Deus, 1975, p. 123).

Assim como os portugueses queriam entrar no "sertão" em busca de metais preciosos, os jesuítas queriam entrar no "sertão" para catequizar os índios. Segundo Oliveira Lima (2000, p. 60), desejava-se fundar uma nova vila que servisse de base para as excursões pelo interior do Brasil. Procurou-se, então, um lugar mais conveniente que São Vicente para a construção de um colégio destinado à catequese. $^{4}$

José de Anchieta relata a Santo Ignácio de Loyola que decidiu se mudar para o planalto, para que a manutenção do colégio fosse mais fácil, tendo em vista as dificuldades que a subida da Serra do Mar impunha. Disse que:

"para sustento destes meninos, a farinha de pau era trazida do interior, da distância de 30 milhas. Como era muito trabalhoso e dificil por causa da grande aspereza do caminho, ao nosso Padre [Manoel da Nóbrega] pareceu melhor no Senhor mudarmo-nos para esta povoação de indios, que se chama Piratininga" (Anchieta, 1554, p. 143).

Foi escolhido um lugar próximo aos rios Tamanduateí e Anhangabaú. Em 25 de janeiro de 1554 foi rezada a primeira missa neste lugar, ocasião que

'. Fvidência dc que tanto os portugueses, quando os jesuítas, queriam entrar pelos sertôes é o relato de Anchieta a Santo Ignácio de Loyola: "Estando nosso padre na Bahia de Todos os Santos, determinou Sua Alteza mandar doze homens pelo sertão a descobrir ouro, que diziam existir. para o que o Govemador Tomé de Souza pediu um padre, que fosse com eles em lugar de Cristo, a fim de não irem desamparados. (...) Eles vão buscar ouro, e ele vai buscar tesouro de almas, que naqueles lugares há muito copioso".

\footnotetext{
${ }^{5}$. Farinha de mandioca.
} 
passou a ser considerada a fundação da cidade de São Paulo (Madre de Deus. 1975, p. 124). O cacique Tibiriçá, que recebeu como nome de batismo Martim Afonso, mudou-se para este novo lugar, erguendo sua aldeia onde atualmente se encontra o Mosteiro de São Bento (Madre de Deus, 1975, p. 124). ${ }^{6}$

Em 1560, os jesuítas, tcmendo que a nova vila não prosperasse, pediram para que o Governo-Geral do Brasil extinguisse a Vila de Santo André. Cumpriu-se a ordem e em 1560 foi oficializada a vila de São Paulo de Piratininga, com a mudança do pelourinho de Santo André para São Paulo. Os índios e portugueses que viviam naquela região tiveram que se mudar para duas localidades, que receberam o nome de Nossa Senhora dos Pinheiros e São Miguel. ${ }^{7}$ (Madre de Deus, 1975, p. 125).

No colégio de São Paulo, as atividades religiosas das mulheres eram as seguintes:

"Seguimos a mesma ordem na doutrina dos indios: chamam-se todos os dias duas vezes à Igreja, a toquc de campainha, ao qual acodem as mulheres ora uma ora outras, e não só aprendem as orações na própria lingua, mas lambém ouvem práticas e são instruidas no conhecimento das coisas da fé" (Anchieta, 1556, p. 22).

Já as atividades dos "curumins" eram as seguintes:

"Expliquei suficientemente na carta anterior como se faz a doutrinu dos meninos: quase todos vêm duas vezes por dia à escola, sobretudo de manhã; pois de tarde todos se dão à caça ou à pesca para procurarem o sustento; se não trabalham não comem. Mas o principal

$\because$ Por isso a rua de São Bento, que liga o mosteiro de São Bento ao Convento de São Francisco (onde fica a Faculdade de Direito da USP), chamava-se rua de Martim A fonso.

${ }^{7}$. Atualmente Nossa Senhora dos Pinheiros compreende os bairros de Pinheiros, Lapa (antiga limboaçava), e os municípios de Usasco e Carapicuiba, posto que nesta região o Rio Pinheiros deságua no Rio Tietè. Por sua vez, São Miguel corresponde atualmente ao bairro de São Miguel Paulista, na zona leste de São Paulo. E ao lado de São Miguel Paulista, fica o bairro de Guaianazes. 
cuidado que temos deles está em lhes declararmos os rudimentos da fé, sem descuidar o ensino das letras; (...) Mas, tememos que chegando eles à idade adulta voltem aos antigos costumes, ou por vontade dos pais ou com o tumulto da guerra, que dizem se prepara muitas vezes, $e$ quando se quebra a paz entre eles e os cristãos" (Anchicta, 1556, p. 23-24).

Anchieta também procurou aprender a língua dos indios: ele é o autor da primcira gramática da língua tupi. entitulada "Arte de Gramática da Língua Mais Usada na Costa do Brasil" A forma de disposição das cadeiras em fileiras em uma sala de aula é criação da Companhia de Jesus, para que uma criança não tivesse como conversar com a outra.

O balanço final das atividades dos jesuitas no Brasil é que foram eles os únicos que defenderam os indios contra a escravidão, por meio da construção de missões. Denunciaram abusos que ocorriam por aqui por parte dos colonos. (Lima. 2000. p. 41).

\section{A Família Indígena face o Direito Europeu}

Dentre os problemas relatados por Anchieta em suas cartas, o que tinha importante relevância jurídica era a questão do casamento.

Como se sabe, a estrutura familiar dos índios era diferente da dos europeus. Enquanto na Europa ocidental a regra era a monogamia, aqui no Brasil um índio tinha várias mulheres, e uma índia tinha vários homens. Também eram comuns casamentos entre parentes. Anchieta descreve parte da situação: "(...) as mulheres andam nuas e não se sabem negar a ninguém, antes elas mesmas acometem e importunam aos homens, lançando-se com eles nas redes, porque têm honra dormir com os cristãos" (Anchieta a, 1554, p. 13).

Esta estrutura familiar era diametralmente oposta ao que era instituído pela Igrcja Católica, e também pelas Ordenações Manuelinas do Reino de Portugal. O casamento, para a Igreja Católica, é uma instituição cuja finalidade é possibilitar a procriação. Os impedimentos para o casamento são regras que se desenvolveram no 
direito canônico. para evitar que parentes muito próximos se casem, de modo a reduzir a probabilidade de filhos defeituosos. Assim, estas estruturas familiares dos indios eram abomináveis segundo o costume europeu, e os casamentos eram concubinatos, seja em razão do modo de vida do casal (informalidade), seja em razão dos atributos pessoais do casal (violação de impedimentos matrimoniais).

O Quinto Livro das Ordenações Manuelinas estabelecia penas para quem casasse duas vezes:

Ordenações Manuelinas, Livro V. Título XV.

Do que ca $\square$ a com duas molheres. E da que ca $\square$ a com dous maridos.

Todo homem que $\square$ endo ca $\square$ ado, e recebido com hua molher, e nom $\square$ endo della apartado per Juízo da Igreja se com outra casar, e $\square$ e receber, moura por ello: e todo daño que as molheres receberem, e todo o que delas levar $\square$ em razam, corregua- $\square$ e por os bens delle como for Dereito. E e $\square$ ta me $\square$ ma pena aja toda molher que dous maridos receber, e com elles ca $\square$ ar, ora ambos os matrimônios $\square$ o $\square$ em inválidos por Dereito, ou hum delles.

Eis o que Anchieta descreve sobre a situação: (Anchieta, 1554, p. 150)

"Juntam-se a isto os matrimônios contraidos com os mesmos consangüineos até primos direitos, de maneira que. se queremos receber algum para o batismo, por causa do laço de sangue é dificilimo encontrar-se mulher com a qual possa casar. O que é para nós não pequeno impedimento, pois não podemos admitir ninguém à recepção do batismo conservando a concubina"

Maria Bcatriz Nizza da Silva (1984, p. 32), professora que estudou profundamente a questão do casamento no Brasil colônia, aponta que outro 
problema prático enfrentado por Anchieta -- evidentemente sem solução -- era estabelecer quem era a primeira mulher de um indio, ou a mais importante, pois é com esta que se celebraria o casamento católico. Dessa forma, ninguém podia ser admitido para a fé católica.

Anchieta constata que a "importação" do direito europeu - tanto o direito português, quanto o direito canônico - para ser aplicado aos indios guaianazes não era possível, pois não só seria desprovido de eficácia, como também descumpriria a sua finalidade, que era a de servir para que as pessoas vivessem segundo a fé cristã. Assim, só restava fazer um apelo surpreendente a Santo Ignácio de Loyola: (Anchieta, 1554, p. 150).

“(...) por isso purece-nos sumamente necessário que se mitigue nestas partes todo o direito positivo, de maneira que possam contrair-se matrimônios em todo os graus, exceto de irmãos com irmãs. O mesmo é necessário tumbém se fazer noutras leis du Santa Madre Igreju, pois, se os quiséssemos obrigar a elas no presente, não há dúvida que não quereriam dispor-se a seguir a fé cristâ".

Com efeito, não houve um abrandamento do direito canônico; e provavelmente Santo Ignácio de Loyola não podia fazer nada a respeito. Tanto que o Concílio de Trento, que, entre outras coisas, reformou as regras sobre o matrimônio, manteve severas punições para este caso. E o próprio Anchieta acabou depois mudando de idéia, ao relatar em 1560 que trabalhava continuamente para a conversão dos indios à fé católica e, por conseqüência, aos hábitos europeus de vida familiar: "Porque os adultos, aos quais o mau costume de seus pais quase se converteu em natureza, cerram os ouvidos para não ouvir a palavra de salvação e converter-se ao verdadeiro culto de Deus" (Anchieta, 1560, p. 57). De qualquer modo, é um exemplo interessante que Anchicta experimentou sobre os limites de eficácia do direito, e da inadequação da aplicação de determinadas regras a povos distintos dos quais elas foram criadas. 
O segundo problema enfrentado pelos jesuítas era a situação matrimonial dos portugueses que vieram para o Brasil. Muitos deles eram casados em Portugal e, quando chegavam aqui, juntavam-se com as indias. Isso quando não abandonavam a cultura portuguesa, tornando-se índios.

Anchieta relata a Santo Ignácio de Loyola que os portugueses, ao chegarem ao Brasil, adotavam o modelo de família indigena para suas vidas: (Anchieta, 1554, p. 150).

"São tão bárbaros e indômitos que parecem estar mais perto da natureza das feras do que da dos homens. O que não é tanto de admirar como a tremenda malícia dos próprios cristãos, nos quais encontram, não só exemplo de vida, mas também favor e auxilio para praticarem más ações" (grifos nossos)

O mesmo João Ramalho, que tanto ajudou os portugueses a se instalarem por aqui, parece que não vivia segundo o modelo europeu de família: (Anchieta, 1554, p. 151).

"Este passou quase 50 anos nesta região, junto com uma concubina brasílica [Bartira], e gerou muitos filhos: a salvá-los dedicaram os irmãos da nossa Companhia todos os cuidados e canseiras. pedindo-lhes com toda a mansidão e incitando-os em espírito de brandura a apartarem-se da má vida. Tanto que o P. Manoel de Paiva se valeu muito do laço de sangue bem chegado, que reconheceu existir entre si e o pai deles. e julgou que se poderia conseguir deste modo alguma coisa em favor do mesmo homem"

Era importante para os jesuítas que João Ramalho assumisse o modelo europeu de família, uma vez que ele era genro do cacique Tibiriçá, ou seja, tinha um papel importante entre os guaianazes. Na opinião do Padre Manoel da Nóbrega, a mudança de seu comportamento certamente traria frutos na catequização dos índios: (Nobrega, 1553).

"João Rumalho é muito conhecido e venerado entre os gentios e tem filhas casadas com os principais homens desta Capitania e todos estes filhos e filhas são de uma india, filha dos maiores e mais principais desta terra. De maneira que nele e nela e em seus filhos esperamos ter grande meio para a conversão destes gentios" 
Tudo indica que os esforços dos jesuítas foram em vão. A resposta de João Ramalho aos jesuitas foi a seguinte: (Anchieta, 1554, p. 151).

"Outro irmão do mesmo, advertindo-se de que tivesse cuidado com a Santa Inquisição por seguir alguns costumes gentilicos, responder que vararia com flechas duas inquisições. E são cristãos, nascidos de pai cristão, que sendo espinho não pode produzir uvas"

Os portugueses não degredados de Portugal que moravam na vila de São Paulo nos primeiros anos do século 17 conservaram sua identidade ibérica, já que o objetivo destas pessoas era vir para cá, enriquecer-se e voltar para seu país de origem. Porém, muitos que aqui chegaram se juntavam com outras mulheres. Não podiam casar, ou porque eram casados em Portugal e não podiam contrair segundas núpcias, ou porque a esposa não cra batizada. Por isso, só restava mesmo a estas pessoas viverem em concubinato.

Lições para os dias atuais

Hoje em dia os fatos são outros, mas a essência dos problemas enfrentados por Anchieta continua. O pedido dele para que se mitigasse a aplicação do direito europeu no Brasil é um exemplo extremo das consequiências da importação de um direito para ser aplicado a um outro povo.

A história mostra que. em casos não tão críticos quanto o enfrentado pelo jesuita, houve problemas parecidos justamente pela inadequação de determinadas regras estabelecidas para o povo brasileiro.

Infelizmente existe o hábito no Brasil de "importar" leis de países desenvolvidos, na esperança de que tudo se transforme a partir do momento da sua promulgação, ou que os problemas se resolvam com uma "canetada" A realização de estudos de direito comparado é importante. para conhecer experiências já realizadas, c quais foram os acertos e erros ao se estabelecer a norma analisada. Porém não se pode confundir direito comparado com direito importado. Diversas 
leis não produzem a eficácia desejada, pelo simples fato de que não tiveram a nossa sociedade como objeto.

Em relação à união estável e ao concubinato, a realidade está aí para mostrar que este tipo de entidade familiar (sobretudo a união estável) ainda persiste, apesar de toda repressão que sofreu nos séculos 19 e 20. Assim como é um absurdo entender que os indios viviam em pecado só por pertencerem a uma civilização diferente da dos europeus, é igualmente um absurdo achar que as pessoas que optam pela união estável não sabem o que fazem, ou que são pecadoras. Porém, esta questão ainda é bastante discutida hoje em dia.

$\mathrm{O}$ art. 226 da Constituição Federal de 1988 trouxe diretrizes para o direito de família brasileiro. Estabelece modelos de família, autoriza o divórcio, entre outras coisas.

Grande polêmica existe sobre o art. 226. $\S 3^{\circ}$. que estabelece o seguinte:

Art. 226.

$\S 3^{\circ}$. Para efeito da proteção do Estado, é reconhecida a união estável entre o homem e a mulher como entidade familiar, devendo a lei facilitar sua conversão em casamento.

Tem-se interpretado que, em cumprimento ao mandamento constitucional, não se pode nem se deve conferir ao convivente os mesmos direitos conferidos ao casado. Com a promulgação do Código Civil de 2002, esta questão reacendeu-se, pois um código deve ter a pretensão de sistematizar estas matérias.

$O$ fato de o casal escolher como modelo de familia ou o casamento, ou a união estável, é manifestação do livre desenvolvimento da personalidade e, em algumas situações, pode ser interpretado como o simples resultado de uma história e cultura familiar que, instintivamente, leva as pessoas a optarem por um modelo de constituição de familia diferente do desejado pelo legislador. A concepção de que o Estado tem o direito, por meio da lei, de impor um modelo "desejável" de família, cuja diferença atual está em celebrar ou não um ato do casamento, é incondizivel com o Século 21. É absurda a idéia de que as pessoas são incapazes de escolher o 
que é melhor para si, e que só o Fstado, ou a elite pensante, sabe o que é bom para as pessoas. Ou. em última instância, aceitar que concepções pessoais sejam impostas às demais pessoas em uma sociedade democrática e pluralista. ${ }^{8}$

O verdadeiro problema não é considerar indesejável a união estável, ou de qualquer outro regime de vida familiar, ou se esta é um modelo indesejado, nos termos da Constituição, ou ainda discutir se estas pessoas podem ou não ter o mesmo tratamento que a pessoa casada. Com efeito, deve-se pesquisar sobre por que determinadas pessoas preferem casar, e outras pessoas preferem se juntar. Com base nos resultados destas investigações, aí sim devem ser criadas as distinções entre o casamento e a união estável, e os direitos e deveres das pessoas que escolhem estes regimes.

É preciso avançar o estágio atual do direito de família brasileiro. Argumentos tais como "se os mesmos direitos da pessoa casada forem conferidos ao convivente, não existirá diferenças entre os regimes", ou "a proteção do convivente deve ser feita pela jurisprudência, já que a união estável não é digna de disciplina legal" só evidenciam que o direito brasileiro não sabe qual o problema a ser resolvido, muito menos se dá conta das raizes históricas do mesmo.

Por fim, nada obsta que daqui a 500 anos criticas sejam feitas ao estágin atual do direito de família brasileiro, no sentido de que as normas vigentes que desqualificam a união estável representem uma certa discriminação mascarada de parcela da população brasileira.

Referências Bibliográficas

ABREU, João Capistrano de. Capitulos de História Colonial. 7.ed. Bclo Horizonte: Itatiaia: São Paulo, Publifolha. 2000.

ANCHIFTA, José de. "Carta do Quadrimestre de Maio a Setembro de 1554, Dirigida por Anchieta a Santo Ignácio de Loyola, Roma" São Paulo, $1^{\circ}$ de setembro de 1554. In Associação Comercial de São Paulo (org). Minhas Cartas - Por José de

${ }^{8}$ O mesmo raciocinio vale para a discussão das uniðes entre pessoas do mesmo sexo. Se duas mulheres querem se casar, ou se dois homens querem sc casar, tais fatos são problemnas que só dizem respeito a estas pessoas. Por serem tão cidadăs quanto os heterossexuais, têm direito que seja feita uma regulamentação jurídica de sua situação familiar, já que a opção destas pessoas de viverem juntas é um assunto de natureza privada. cabendo ao autor deste texto, à sociedade, e ao Estado, respeitarem esta decisão. 
Anchieta. São Paulo: Associação Comercial de São Paulo, Editora Melhoramentos, Páteo do Collegio, 2004. p. 140-158.

"Carta Trimestral, de Maio a Agosto de 1556, pelo Irmão Anchieta" São Paulo, agosto de 1556. In: Associação Comercial de São Paulo (org). Minhas Cartas Por José de Anchieta. São Paulo: Associação Comercial de São Paulo, Editora Melhoramentos, Páteo do Collegio, 2004. p. 22-25.

"[Carta] Do Ir. José de Anchieta ao Geral P. Diogo Laínes, Roma" São Vicente, $1^{\circ}$ de junho de 1560. In: Associação Comercial de São Paulo (org). Minhas Cartas … Por José de Anchieta. São Paulo: Associação Comercial de São Paulo, Editora Melhoramentos, Páteo do Collegio, 2004. p. 56-76.

ANCHIETA a, José de. "Carta do Irmão José de Anchieta a Santo Ignácio de Loyola" Piratininga, julho de 1554. In: Associação Comercial de São Paulo (org). Minhas Cartas - Por José de Anchieta. São Paulo: Associação Comercial de São Paulo, Editora Melhoramentos, Páteo do Collegio, 2004.

BRASIL. Constituição da República Federativa do Brasil. 5 de outubro de 1988.

LIMA, Oliveira. Formação História da Nacionalidade Brasileira. 3. ed. Rio de Janeiro: Topbooks; São Paulo: Publifolha. 2000.

MADRE DE DEUS, Frei Gaspar da. (1715-1800). Memórias para a História da Capitania de São Vicente. Prefácio de Mário Guimarães Ferri. Belo Horizonte: Ed. Itatiaia; São Paulo: Editora da Universidade de São Paulo, 1975 [1. ed. Lisboa: Typografia da Academia, 1797].

PORTUGAL. Ordenações Manuelinas. Disponível em: $<$ http://www.uc.pt/ihti/proj/manuelinas/ORDEMANU.HTM $>$ Acesso em: 04.07.2004.

NÓBREGA, Manoel da. "Carta do Padre Nóbrega a João Ramalho" 1553. Extraído de BONAVIDES, Paulo; CAMPOS, Roberto. Textos Políticos da História do Brasil.v. 1. 3. ed. Brasília: Senado Federal, 2002.

SILVA, Maria Beatriz Nizza da. Sistema de Casamento no Brasil Colonial. São Paulo: T.A. Queiroz Editor e Editora da Universidade de São Paulo, 1984. 